\title{
MENTAL HEALTH REHABILITATION IN ICD CLASSIFICATION FOR PEOPLE WITH DISABILITY IN UKRAINE
}

\author{
Olha Herus, Tereza Klymus, Marta Kozak, Uljana Yatschyn (Lviv) \\ Lviv Polytechnic National University, Lviv, Ukraine
}

-Ph.D., Assistant, Department of Sociology and Social Work

- Ph.D., Senior Lecturer, Department of Sociology and Social Work

- Ph.D., Associate Professor, Department of Sociology and Social Work

- Ph.D., Assistant, Department of Sociology and Social Work

Background:The first two decades of life are characterized by rapid growth and significant changes in the physical, social and psychological development of person. In the World Health Organization (WHO) international classifications, health conditions such as illnesses, disorders and injuries are generally classified in ICD-10 (International Classification of Diseases 10th Revision), that provides an etiological basis. ICF-DP (International Classification of Functioning, Disability and Health)is intended for use by clinicians, educators, family members, researchers, administrators, and the community in social and political spheres that have documented evidence of the health and functioning of children and teenagers. ICF-DP offers conceptual frameworks and a single standardized terminological language to refer to problems encountered in infancy, childhood and adolescence, including body functions and structures, activity and limited participation, as well environmental factors that are important for children and adolescents.

Purpose: The study aims to identify importance of implementation ICF in rehabilitation process as multidisciplinary tools in solving the problem of mental health care in Ukraine for people with disability.

Methods: Theoretical research methodswere used to determine the current situation in time of reforming medical and social sphere in Ukraine according to social and medical services for people with disability. Qualitative content analysis of the questionnaires collected from specialists about implementation ICF in practical work in rehabilitation center in Lviv.

Results:ICF classifies health and health-related conditions of person. Thus, the unit of classification is the categories in health domains and domains related to health. Therefore, it is important to note that in the ICF individuals are not units of classification; it means that ICF does not classify people but describes the situation of each person within a range of safe or medical domains. In addition, the description is always made in the context of environmental factors and personal factors.

The ICF proposes to consider the concepts of "health" and "disability" in a new light: any person may experience deterioration in their health, that implies some degree of limitation of their ability. Moreover, the ICF takes into account the social aspects of disability and does not consider disability solely as "medical" or "biological" dysfunction (Nieto-Moreno, Gimeno, Adán, García- 
Olmos, Valle, Chatterji, Leonardi\&Ayuso-Mateos, 2006). By including contextual factors, including the environmental factor, the ICF makes it possible to take into account the environmental impact of human activity.

The most difficult is to use ICF in practice of rehabilitation by specialists. ICF is a tool to provide a unified approach in rehabilitation (a kind of "universal language"), whereby experts from various specialties and medical institutions can understand each other. ICF allows you to practice the basic principles of rehabilitation: patient-centered and problem-oriented principles, personalized, multi-disciplinary principle and the biopsychosocial model of illness and disability. The thing that gives ICF for professionals is the concept of human health where human being is seen with three biopsychosocial perspectives: as a biological object, as a part of society, as an individual and a person with their attitudes, character, experience and vision of the world. Before the creation of the ICF conception of human being and its health was different in different countries and clinics. The main aspect of rehabilitation focused around the violations of functions and structures, which led to active medical care, but contributed to the neglect of other, non-medical problems of the patient. That is why the WHO recommends the use of the basic principles contained in ICF (Classification of Functioning, Disability and Health (ICF), 2013).

So, the implementation of ICF leads to change the way of thinks those specialists that work with a patient and to see another point of view about the problems of disabled person. The specialist's attention is shifted to functioning rather than function, which is manifested by a better perception of the concepts of activity (activity and participation) and context, factors (personal factors and environmental factors).

One of the main conditions for the effective use ICF is to work in a multidisciplinary team. Human being and his functioning in life are complex phenomena, and rehabilitation is an even more complex process. One specialist is not able to assess the patient's condition objectively in all aspects of functioning. If 11 among all participants in the team, functional responsibilities are distributed and the corresponding ICF domains are meaningful, this allows us to share the work and remove the load from the team as a whole. This form is the basis for managing the rehabilitation team. The absence of one of the specialists in the team can lead to ignoring of patient problems falling within the competence of this specialist (Classification of Functioning, Disability and Health (ICF), 2013), which will negatively affect the rehabilitation as a whole or may even become the reason why it will not be successful. In rehabilitation, the rule is that "specialists are not ready to see the patient's symptoms and problems that they don't know about, even if these symptoms and problems are obvious." ICF is used not only in medical, but also in social rehabilitation. Occupational therapists, physical therapists, and social workers use the ICF worldwide effectively. As their experience with the ICF shows, the use of codes is optional. Specialists formulate patient 
problems in their own words or using the ICF domain name formulations from the official full version (Meljnykova, Bujlova, Bodrova, Shmonyn, Maljceva \& Yvanova, 2017; Gholyk, Moroz \& Poghorelova, 2011; Measuring Health and Disability: Manual for WHO Disability Assessment Schedule, 2010).

The goal is rehabilitation. A mandatory component of working with each patient is to determine the purpose of rehabilitation. An ICF is needed to find a goal. Formulating the problems in the rehabilitation diagnosis, it is necessary to single out the key ones from which the patient suffers and his functioning is limited. The main outcome of the team meeting is finding the goal of rehabilitation for a particular patient. If in other areas of medicine 17 this may not be so important to formulate, then in rehabilitation without a goal it is impossible to build work. The goal of rehabilitation is the result of a discussion of a patient with team and the formation of consensus on the patient's prospects for his future fate. The goal is closely related to the forecast. The goal is set according to the mnemonic rule SMART: S - Specific, M - Measurable, A - Attainable, Achievable, R - Relevant and T - Time-bound (Bujlova, 2013).

Conclusion: The ICF concept and its proper use should be trained by all specialists from the doctor to social worker.

Key words: international classification of functioning, ICF, rehabilitation, multidisciplinary team, management, rehabilitation diagnosis, capacity, implementation, activity, function, contextual factors.

\section{References:}

Meljnykova, E.V., Bujlova, T.V., Bodrova, R.A., Shmonyn. A.A., Maljceva, M.N., Yvanova Gh.E. (2017). The use of the international classification of functioning (ICF) in outpatient and inpatient medical rehabilitation: an instruction for specialists//Bulletin of Restorative Medicine, № 6 (82).

Bujlova, T.V. (2013). International classification of functioning as a key to understanding the philosophy of rehabilitation// Medial. № 1 (6). P. 26-31.

Gholyk, V.A., Moroz, E.N., Poghorelova. S.A. (2011). The use of the international classification of functioning, disability and health in expert neurological practice // International Neurological Journal. № 5 (43). P. 104-110.

Classification of Functioning, Disability and Health (ICF). Exposure draft for comment. October 2013. Geneva: WHO, 127 P.

Measuring Health and Disability: Manual for WHO Disability Assessment Schedule (WHODAS 2.0) / edited by TB Üstün, N Kostanjsek, S Chatterji, J Rehm. / WHO Library Cataloguing-inPublication. 2010.

Nieto-Moreno, M., Gimeno Blanco, P., Adán, J., García-Olmos, L., Valle, J., Chatterji, S., Leonardi, M., Ayuso-Mateos, J.; Grupo de Investigación ITACM (2006). Applicability of the ICF in measuring functioning and disability in unipolar depression in Primary Care settings. Actas Esp Psiquiatr. 34(6). P.393-396. 